\title{
Low-Cost Housing: A Cost Management Model for Process Integration and Evaluation
}

L. Obi ${ }^{a *}$ and M. Arif ${ }^{b}$ and J. Goulding ${ }^{\mathrm{c}}$

${ }^{a}$ Department of Built Environment, University of Wolverhampton, Wolverhampton, United Kingdom; ${ }^{b}$ School of Architecture and the Built Environment, University of Wolverhampton, Wolverhampton, United Kingdom, ${ }^{c}$ Department of Built Environment, University of Wolverhampton, Wolverhampton, United Kingdom

*a L.obi@wlv.ac.uk,

bmohammed.arif@wlv.ac.uk

cJ.Goulding@wlv.ac.uk 


\section{Low-Cost Housing: A Cost Management Model for Process Integration and Evaluation}

Effective cost management is a vital requisite for successful Low-cost housing projects (LHPs) management and delivery. Whilst several attempts have been made to develop appropriate structured models for cost management practice, many of these models are fragmented and do not capture a holistic representation of the system components or their interrelationships in LHP settings. Moreover, these models are predominantly descriptive by nature - only identifying the components of cost management and not how they can be implemented within LHP settings. This research adopts an explicit sequential mixed research design to develop a bespoke LHP cost management model for process integration and evaluation in Nigeria. This identifies the structures and interrelationships needed to conceptualise and implement cost management practice effectively. Research findings highlight eight important techniques. These include target costing, approximate estimating, site meetings, Earned Value Analysis, on-site resource control, cash flow analysis, cost reporting and cost aggregation. However, it also needs to be acknowledged that it is important also to have: a well-developed client brief; detailed project designs and accompanying specifications; effective project planning and supervision; and competent teams (client and contractor) to discharge responsibilities. The importance of early contractor involvement was also seen as a core lever for success throughout the pre-design, design, and construction stages of LHP. The resulting model standardises cost management practice to provide a systematic 'blueprint' beneficial to project managers, cost managers and project management teams in evaluating and managing CMS processes more effectively in LHP settings. It is expected that the project department in Housing agencies adopts this model as a requirement for cost management practice in LHPs in Nigeria.

Keywords: cost management; Low-cost housing project; project management team; performance indicators; system model 


\section{Introduction}

Low-cost housing projects (LHPs) are typically initiated to improve the supply of adequate 'affordable housing' to low and low-middle income groups. While investment in LHP is a means of meeting the growing housing demand of a vast majority of low and low-middle income populations in many countries, it is also a recognised avenue for sustainable economic growth (UN-Habitat, 2012). Acknowledging this, low-cost housing schemes in many developing countries like Nigeria are typically government initiated, where the projects are executed through government bodies such as housing agencies, authorities and corporations. Its effective provision requires the engagement of a number of conjoined systems and structures, including contextual drivers, prototype management styles, organisational systems, and financial business control measures. These underpinning needs are considered ‘essential prerequisites' for successful LHP delivery. Low-cost Housing in Nigeria is no exception (Federal Ministry of Housing Land and urban Development (FMHLUD), 2012), where in many developing countries new-build residential mass housing developments are deployed, often located in the same geographical locality and executed under similar contract and management systems (Adinyira., Botchway, \& Kwofie, 2012; Obi, Arif \& Kulonda, 2017). Given the mass housing provision, the project management environment differs significantly from one-off building projects in many ways (Jacomit \& Granja, 2011; Obi et al., 2017). The first point to observe is the high number of dwellings on-site, using repetitive and concurrent delivery features supported by prototype management approaches. The second issue to observe is the financing arrangement, where many public-sector clients depend on world project financing bodies (whose lending controls have significantly tightened since the Global Financial Crisis in 2008) to fund these 
projects (Smith, 2014). As a result, budgets are often tightly controlled, based on available government funds and affordability requirements of the project beneficiaries.

Consequently, it is normal to engage Project Management Teams (PMT), which typically comprise of a housing agency supervision team, consultant and contracting personnel (Ogbu \& Adindu, 2012) to deliver these projects within the defined budgets. However, in context of LHP settings in Nigeria many PMT's have failed to control costs, with cost overruns often exceeding 100 per cent of initial budgets on projects since post-independence (Akinde 2012; FMHLUD, 2012). There are several reasons identified for this, such as: ineffective techniques/ tools, variations, poor communication plans, increased task complexity, stakeholder incompetence, poor time management, under-budgeting, market variability, poor feasibility and project analysis, poor on-site financial management, cost-related waste resulting from adverse weather conditions, weather conditions, and unanticipated change orders (Rwelamila,2012; Obi et al., 2017; Sinesilassie, Tabish, \& Jha, 2018). These factors are invariably often a result of ineffective cost management system (CMS).

Acknowledging these challenges, CMS is not just a collection of tools or techniques for cost control (Potts, 2008; Benjaoran, 2009), but more a holistic administrative framework for managing costs throughout the project life cycle. Typically, such frameworks highlight appropriate elements (techniques, process approaches and moderation mechanisms) and their interactions to assist cost managers and project teams in implementing and achieving effective cost management outcomes. However, on this subject alone, it is recognised that there is a paucity of research specifically identifying these interrelationships and interceding constructs. Where for example, Ahiaga-Dagbui, Smith, Love, and Ackermann (2015) conceptualised these connections and the dynamics between the various system elements, noting that they 
were crucial for addressing cost management issues rather than listing or ranking the causal factors. Given this, it is therefore proffered that such constructs should be uniquely established; in particular, those which [inter alia] affect the success or failure of LHPs. This study, therefore, seeks to uncover new understanding and insight into these CMS elements and interrelationships by developing a bespoke cost management system (CMS) model for LHP delivery. This paper presents the following stages in this development process:

i. The identification of appropriate techniques and success drivers needed for effective cost management within LHP settings;

ii. The evaluation of interrelationships between the identified techniques, success drivers (and subsequent influence on cost management) at each process stage within a LHP setting;

iii. The conceptualisation, development and validation of a bespoke Cost Management Model for Process Integration and Evaluation within LHP settings.

\section{Cost Management Models and Systems}

\subsection{Historical Development}

A construction project may not succeed without appropriate planning and control at all stages of the project lifecycle. Therefore, a representation of the cost management processes and procedures are meaningful roadmaps to assist cost and project managers in decision making and management. Several cost management systems (CMS) and models have been developed for Architecture, Engineering and Construction (AEC). Numerous attempts have also uncovered a number of drivers and techniques for improving cost management implementation (Oladapo, 2001; Kern \& Formoso, 2006; Liu \& Zhu, 2007; Gorog, 2009; Jacomit \& Granja, 2011: Stephenson, 2015; Obi et al., 
2017; Omotayo \& Kalatunga, 2017). However, from a cost management perspective, extant literature has not explicitly identified the key causal drivers or contextual forces that govern LHP success within LHP settings.

Cost management can be defined as the process of planning, estimating, coordinating, controlling and reporting of all cost-related aspects of a project to ensure delivery within approved budget (Ashworth, 2010; Obi et al., 2017). This typically involves an understanding of what, how and why costs are incurred on projects, and proactively taking the necessary actions needed to control them considering all relevant information. Various attempts have been underway to model some components of CMS in one form or another, and approaches for aligning this to LHP delivery vehicles are rare. Where, Alashwal et al., (2011) observed that a model was considered a representation of those aspects of a structure being investigated, including the relationships between the variables and concomitant context. In this respect, Kern and Formoso (2006) developed an integrated cost management model which integrated: target costing (embodying lifecycle costing and value engineering process), operational estimating (to develop activity costs for assessing the impact on target project costs and duration), and S-curve from earned value analysis (to assist in the monitoring, forecasting, and control of cost resources at various project milestones). However, this did not fully integrate all relevant success drivers for effective operation within the system. Liu and Zhu (2007) developed a theoretical framework that identified the critical factors needed for effective cost estimation during each project phase of a conventional construction project. Similarly, Benjaoran (2009) and Gorog (2009) designed new systems for cost control and cash flow management underpinned by earned value concept management techniques; but these did not explicitly identify the success drivers needed for successful implementation. A total cost management process 
model underpinned on the process management principles of Plan Do Check Act (PDCA) cycle was developed as a systematic approach for managing costs throughout a project’s life cycle (Stephenson 2015). Omotayo and Kalatunga (2017) also developed a framework for continuous improvement in post-contract cost control for building projects in Nigeria - albeit only applicable for cost control during the construction phase.

In the context of LHP, Oladapo (2001) developed a cost management framework for LHP. This framework acknowledged the need to integrate value engineering and life-cycle costing techniques into a design to cost management approach, but this did not show a clear link on the structure and relationship of framework elements or successful implementation factors. On this theme, Jacomit and Granja, (2011) developed a target costing framework for Brazilian LHP’s, which identified early contractor involvement and team collaboration as success drivers for implementing this technique (although not defined in the framework). In addition, Obi et al. (2017) developed a success factor model based on LHP experts for effective cost management. On reflection, the work on CMS and LHP is continuing to provide fertile evidence for continued support. Whilst some of these models have paved the way for additional research, the main challenges seem to rest with underpinning theory and the evidential chain need to deliver success. For example, some of the process-based models are too generic for implementation, as specific controls are required, along with key success factors (to support effective operation and validation). It is also important to acknowledge the need to improve CMS efficacy, including the contextual interrelationships that exist. These are important drivers of the cost management process - the corollary of which impinges on accuracy and overall 'fit for purpose'. The PMT, therefore, needs to have holistic clarity on all interrelationships and CMS parameters. 
Moreover, they also need to appreciate all forces that encompass the LHP management environment in order to support successful delivery (Ahadzie \&Amoa-Mensah, 2010; Adinyira et al., 2012). A holistic model is therefore required that shows such relationships; especially how these relationships and delivery outputs can be utilised in practice - from pre-design through to the construction stages of LHP delivery. This precept underpins the core rationale of this study.

\subsection{Cost Management System: Parameters and Components}

Managing project costs are an essential aspect of project management. As such, the purpose of a CMS should act as a framework through which cost efficiency can be measured, understood and achieved. This is particularly important in the case of LHP's, where the veracity and integrity of the underpinning CMS can significantly influence project outcomes. However, it is also recognised that cost management practice has often been viewed as a complex system. For example, from a Systems Theory perspective, a system should be conceptualised based on the understanding of the causal interactions between the various components within the system's boundary (AhiagaDagbui et al., 2015). Thus, a conceptual framework for understanding the components and dynamics of a system is needed in order to interpret problems and develop appropriate 'balanced’ intervention strategies. Thus, following System’s Theory, an open CMS system should possess: inputs (techniques), processes (management cycle), outputs (performance outcome) and feedback (regulatory) parameters. These relationships are shown in Figure 1; where the parameters and components presented here follow the works of Sanvido (1988), Windapo (2013) and Obi et al. (2017). 


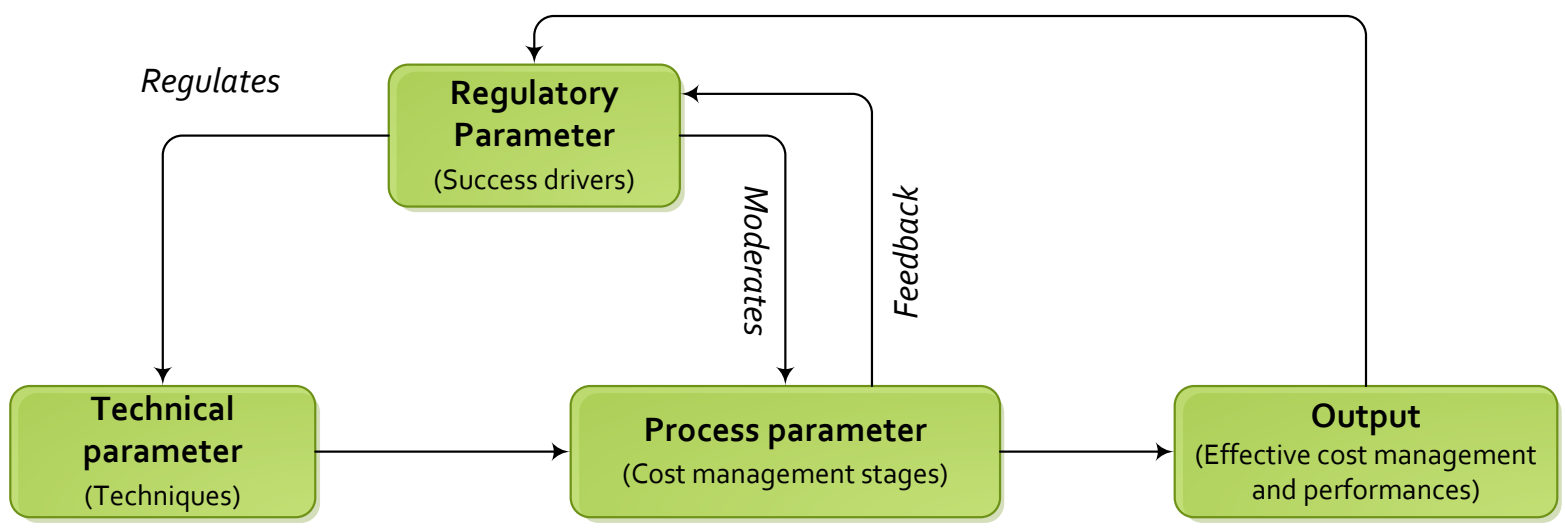

Figure 1: Process view of CMS

Source (Adapted from Sanvido, 1988)

\subsubsection{Technical Parameter}

The technical parameter subsystem embodies the techniques typically employed for managing costs throughout the whole cost management process. Whilst not exhaustive by any means, the main seminal research includes: Kern and Formoso, (2006), Horngren, Foster, Datar, Rajan, and Ittner, (2009), Jacomit and Granja (2011), Azis, Memon, Rahman, Latif, and Nagapan, (2012), Olawale and Sun (2013), Chigara, Moyo and Mudzengerere (2013) and Morad and El Sayegh (2016). Core fields of investigation include: approximate estimating, operational estimating, cost budgeting, cost planning, cash flow analysis, cost reporting, resource (plant, material labour overhead) monitoring, value engineering, target costing, activity-based costing, earned value analysis (EVA), interim valuation, site meetings and cost-value reconciliation. Cost managers typically employ these techniques during various stages of the process cycle in order to plan and control costs. 


\subsubsection{Process Parameter}

The process parameter subsystem hosts the cycle of the cost management process. This process can often engage a number of complex and iterative processes, achieved through four progressive phases:

- Setting: developing project target costs based on the analysis of the client business case;

- Planning: allocating costs to elements of the project to determine estimates for project tasks and activities;

- Budgeting: aggregating established elemental cost estimates on the project timeline to develop an overall cost performance baseline;

- Monitoring: monitoring the cost performance status and managing changes to the cost baseline.

The synergy of operations between techniques and success drivers are fundamentally important as this determines how project resources are deployed. The focus here, being to optimise resource efficiency within the context of the system parameter. The efficiency of operations within the process parameter is typically evaluated by a number of criteria, including: cost and decision effectiveness, cost predictability and cost deviation alerts, realistic project costs and elemental estimates (to complete project activities), effective cost baselines, cost performance indices etc. (Toor \& Ogulana 2010). The core rationale being to generate realistic project target cost (Zimina, Ballard,\& Pasquire, 2012). This includes accurate and representative elemental costing needed for completing project activities at the planning stage (Ashworth, 2010), and operational cost performance baselines for control purposes (Morad \& El Sayegh, 2016). 


\subsubsection{Regulatory Parameter}

The regulatory parameter subsystem is responsible for moderating and supporting effective process implementation within the CMS. This is needed as the drivers within the regulatory parameter can often influence or determine the choice of techniques employed; which in turn affects inputs, processes and concomitant project resources (Olawale \& Sun, 2013; Obi et al., 2017). Thus, the regulatory parameter subsystem helps ensure adherence to predefined cost-performance requirements. From literature, key cost management regulatory drivers are loosely coupled into three themes, representing, team-issues, management and information-issues, or project environmentrelated issues. For example, Gao et al. (2002) identified team-building activities, a core management group for small projects and the need for standard processes and front-end planning. Whereas, Trost and Oberlender (2003) identified process design, team experience and cost information, the time allowed for preparing the estimate, site requirements and the bidding/ labour climate as being critical drivers. This resonates with Tang (2005) regarding the need for effective site management, expenditure control and communication. However, Olawale and Sun (2013) advocated the need for detailed design and specification, team competency, collaboration and effective project planning. This supported Enshassi et al. (2013) findings on the importance of the project team's competence, and the need to secure clear/detailed drawings and specifications. Competence was also raised by Morad and El Sayegh (2016), Obi et al. (2017) and by Hatamleh, Hiyassat, Sweis, and Sweis (2018). From a LHP perspective, Obi et al. (2017) identified nine key success drivers for cost management in Nigeria. These drivers were: competent design team; competent contractor team; early contractor involvement; effective team collaboration and commitment; well-detailed designs and specifications; effective project planning and supervision; adequate and effective cash 
flow; adequate resolution of land compensation issues; and a clear and well-developed client brief. These nine drivers were adopted for further investigation in this paper given the context, contemporary nature of their findings and appropriateness to this study.

The above review of the literature suggests that there would be a significant impact of the various parameters on management practices and processes. Given a critical consideration of the process view of CMS and integration of the same (Figure 1), it is important to incorporate and conceptualise the relevant variables in a systematic model. The study further examines in context, the 14 techniques, four process stage/ outcomes and nine success drivers identified from the literature.

\section{Research Methodology}

\subsection{Underpinning Research Context and Positioning}

Intrinsically, the term 'research methodology' is often accepted to envelop the whole research process, from theoretical underpinning, through to data collection and analysis; the confluence of which should present 'credible' results for informing/shaping knowledge or phenomena (Saunders, Lewis, and Thornhill, 2012). Drawing from the 'research onion’ postulated by Saunders et al., (2012), this research engages both objective and subjective epistemology [to address both context and positioning] in order to meaningfully integrate different perspectives [stakeholders] with context-sensitive data. It presents a value-driven research axiology for uncovering new insight and understanding of CMS and LHP (within the Nigerian context). Given this, it engages a deductive pragmatic approach, acknowledging that cognate and non-cognate stakeholders will more than likely have multiple lens, and several prisms (reflecting their 'reality'. Thus, the research strategy engaged an explicit sequential mixed-method approach (Denzin and Lincoln, 2011; Holt and Goulding, 2014) to not only contextually 
'ground' these findings, but also improve data veracity and validity. Information for the study was gathered from a group of academic experts and construction practitioners drawn from PMTs organisations in the Nigerian LHP sector, the semblance of which included: quantity surveyors, architects, project/construction managers and design engineers. Participants were chosen based on their educational/professional background, expertise and involvement in project cost management and LHPs within structured environments. This was considered necessary to appropriately reflect current CMS practices in LHP and gather relevant and credible information to achieve the study aim.

In summary, it is important to acknowledge the dynamic nature of social constructs and social reality. Thus, this research sequentially engages a series of specific procedure for collecting data in order to capture, appreciate and understand cognate 'meaning'. This includes the engagement of questionnaires, brainstorming sessions and focus groups using 'representative' stakeholders (drawn from academic experts and professionals from client, consultant and contracting organisations that constitute the PMTs in LHP settings with managerial influence on the cost management process). The data analysis phase used descriptive statistical analysis and thematic- content analysis. The research approach and model development process were carried out in four stages.

Stage one of this research was used to establish the techniques and process outcomes required for the model. A brainstorming exercise was used to contextualise CMS to LHP's, cognisant of the Nigerian setting and concomitant needs. A conventional brainstorming session was conducted with six PMT members experienced and involved in various LHPs across the country. The PMT experts consisted of two experts from the housing agency supervision team; two experts from the consultancy team, and two experts from the contractor's management team. This was considered 
necessary to ensure that views from each group are captured given their role distribution and service delivery obligations. Some of the participants were physically present and others were remotely contacted. This session was used to determine the CMS variables that had the highest impact on cost management practice (within the context of this investigation). Stage Two engaged a questionnaire survey with a wider pool of PMT experts in the industry. This was undertaken to validate techniques and process outcomes from Stage One. This survey was distributed to 249 actors, all of which were considered PMT experts in Nigeria. The strategy sampling adopted was 'purposive’, capturing contextual experts in CMS and LHP. From this, 144 questionnaires were returned, representing a 57.83 per cent response rate. The frequency distribution of respondents included: 26 (18.1\%) experts working in housing agency supervision teams; 57 (39.6\%) working with the consultancy teams; and 61 (42.4\%) working with or in contractor teams. The four-point Likert scale ranged from "strongly agree” through to "strongly disagree", as this range was considered appropriate for respondents with a priori knowledge, thereby negating the need for a neutral option (Hartley, 2013). The rationale of this questionnaire was to identify appropriate techniques/methods and performance outcomes appropriate for cost management in LHP settings. Stage Three engaged a second brainstorming session to define the interrelationships of the CMS components and the rubrics needed for the model. This session used the same PMT members involved in Stage One of this research in order to ensure consistency. Finally, Stage Four used a focus group setting to validate the model. The model development process is described in the following section.

\section{Model Development}

The design interrelationships, CMS components and parameters which guide assessment /validation criteria were key considerations in the development of the 
model. In this respect, it was important to embed LHP-specific cost management data into the model. The model development process was undertaken through four distinct phases, using construction experts from the Nigerian low-cost housing sector.

\subsection{Stage 1: Contextualise Techniques and Process Stages Outcomes}

This stage was used to capture effective CMS implementation techniques within the context of LHP's. It was also used to evaluate the effectiveness of process implementation, given the complexity of issues involved. In total, 14 identified techniques and four process stage outcomes from the literature were presented to experts for discussion. This discourse was also used to explain the research concept, context and purpose of this research. From a process perspective, all participants agreed that the four stages and desired outcomes identified were relevant. Regarding techniques, a decision was taken to remove two techniques in order to create greater focus and relevance. Experts’ opined that approximate estimating technique ostensibly applied to cost planning and can be used for resource estimating; value engineering was integrated into target costing process, and cost variance was considered an aspect of earned value analysis process. Moreover, resource monitoring was modified as "onsite project resource control”, and cost aggregation was added to the list as this was considered a more appropriate term than "cost budgeting technique”. Based on this feedback, eight techniques (Figure 2) emerged as being the most appropriate for effective CMS implementation in LHP. Feedback from Stage 1 was then used to develop the questionnaires needed for Stage 2 of this research.

\subsection{Stage 2: Validate Techniques and Process Outcomes}

This stage of the research was used to validate techniques and process outcomes. A questionnaire survey was undertaken with a wider pool of PMT industry experts to 
validate findings from Stage 1. The questions presented in Stage 2 included the eight techniques and four process stage outcomes identified from Stage 1. Respondents were asked to rate their level of agreement on:

- The techniques/methods considered effective for cost management in LHP settings;

- The performance outcomes considered appropriate for each cost management process stage within LHP settings.

The data collected were analysed using frequency distribution statistics to show the number of responses received in each category in respect of the total number of responses (Pallant, 2013). Figure 2 presents the findings of the eight techniques, and Figure 3 presents the results from the four process outcomes. These collective findings and inference from the quantitative analysis were then used to develop the model in Stage 3.

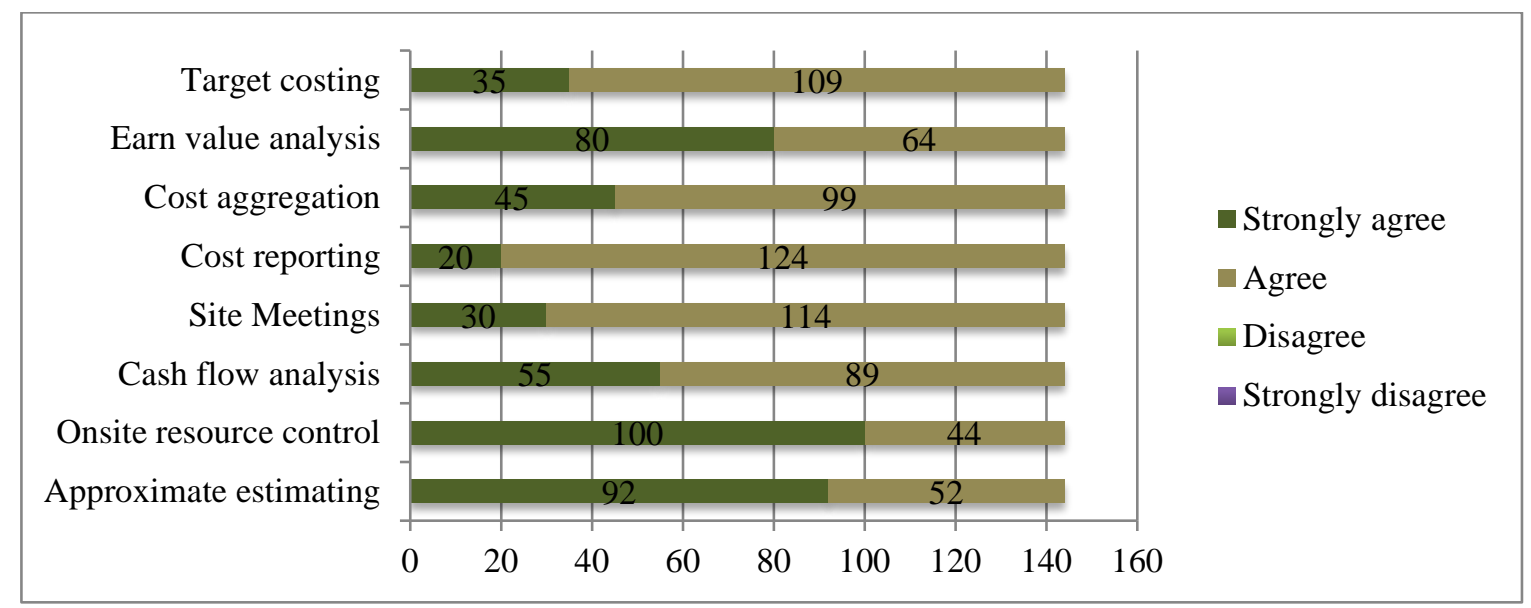

Figure 2: Frequency distribution chart for Cost management techniques 


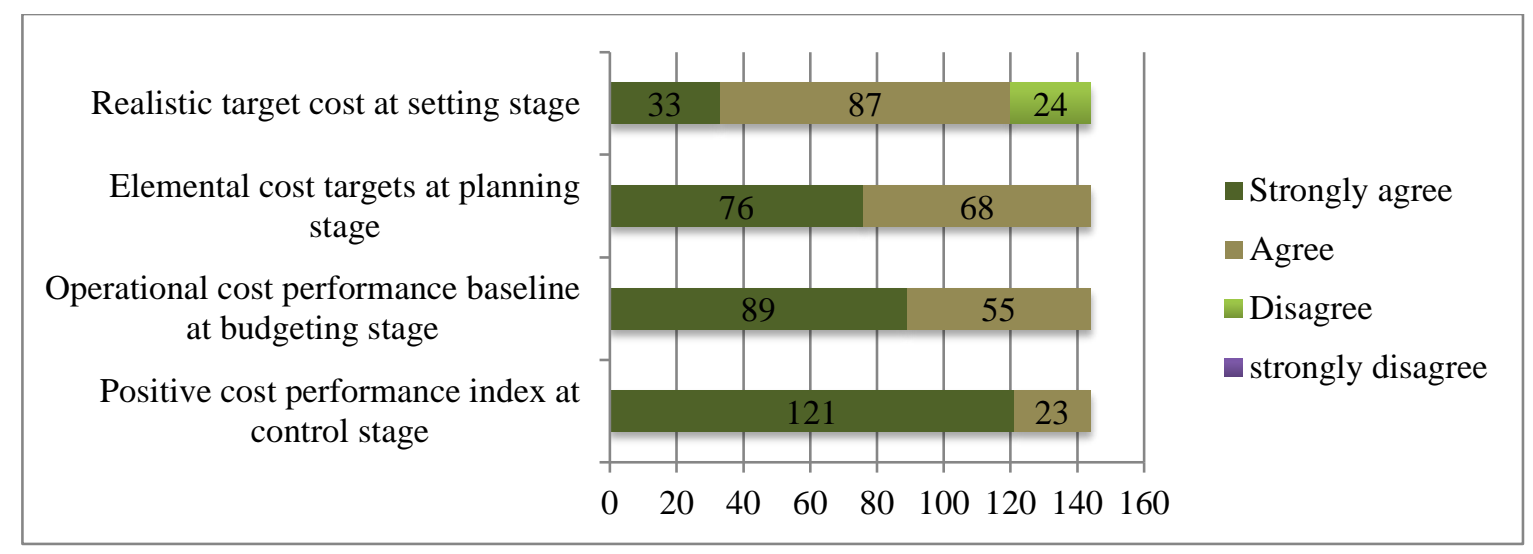

Figure 3: Frequency distribution chart for process stage outcomes

\subsection{Stage 3: Define Interrelationships of CMS Components and Design the}

\section{Model}

This stage of the research was used to develop the model. The approach adopted follows the principles of the system theory Input-Process-Output (IPO) approach. This provides a structured approach for addressing system-oriented problems to identify: i) what inputs are required to achieve the outputs, ii) and to evaluate the choices of methods employed in the process (Sanvido, 1988; Windapo, 2013; MacCuspie et al., 2014; Obi et al., 2017). The IPO approach represents a system with inputs considered as resources/consumables or efforts, and the 'process’ seen as the conversion parameter, with 'outputs' considered the result produced from the process. From this, the design interrelationships and parameters within the CMS were determined. The findings from the quantitative investigations were juxtaposed with the nine success drivers identified from the literature to develop the prototype schema (Figure 4). 


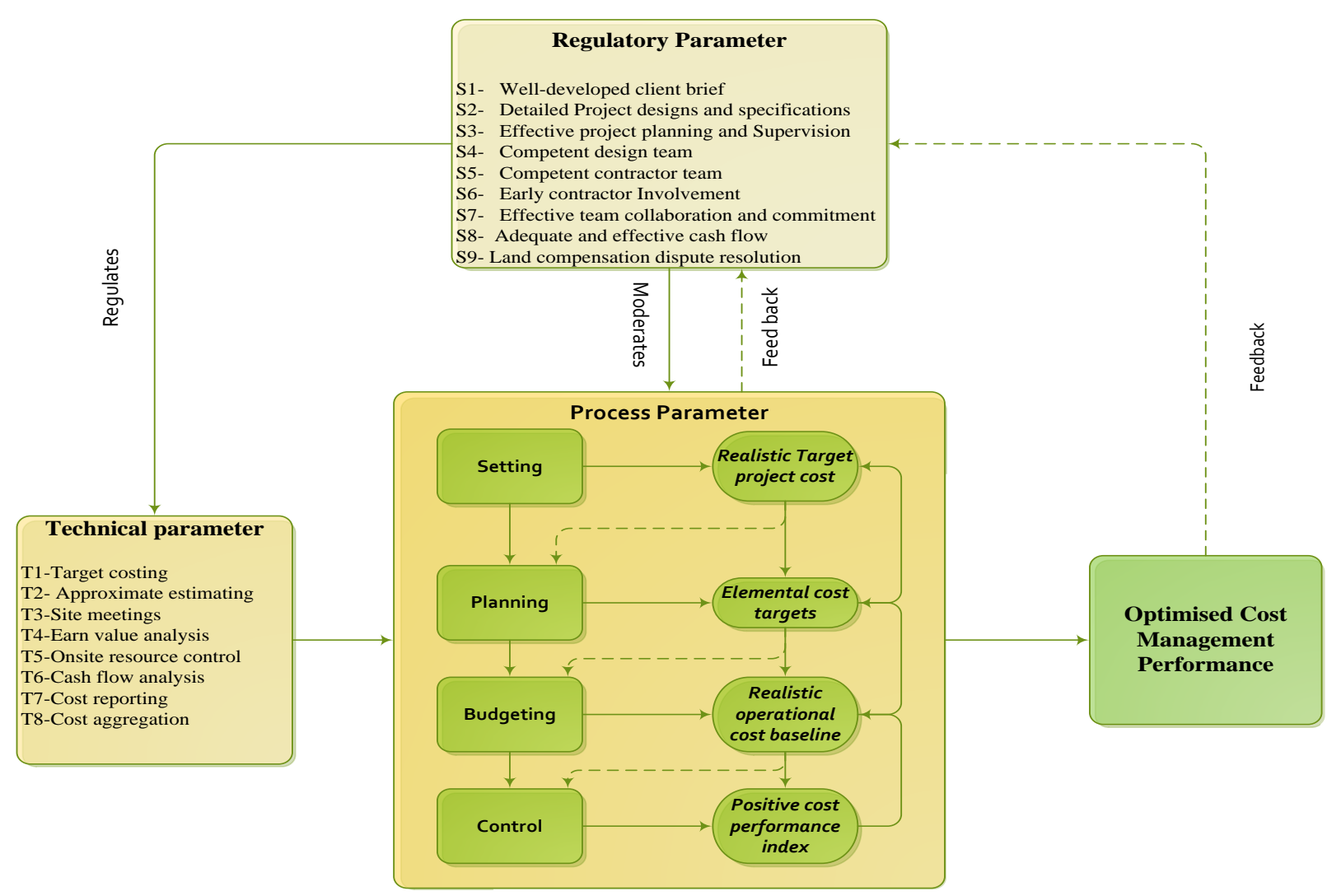

Figure 4: Model Prototype Schema

Figure 4 presents the interrelationships between the technical parameters, regulatory parameters and process parameters, culminating in "Optimised Cost Management Performance”. Experts were required to define the relationship between the identified eight techniques and nine success drivers, with respect to the cost management process stages and outcomes. The results of this session are presented in Table 1. 
Table I: Process Stages, Outcomes, Techniques and Success Drivers

\begin{tabular}{|c|c|c|c|}
\hline $\begin{array}{l}\text { Process } \\
\text { Stages }\end{array}$ & $\begin{array}{c}\text { Process Stage } \\
\text { Outcomes }\end{array}$ & Techniques & Success Drivers \\
\hline Setting & $\begin{array}{l}\text { P1 - Project } \\
\text { target cost }\end{array}$ & $\begin{array}{l}\text { - T1 directly influences } \\
\text { the achievement of P1 }\end{array}$ & $\begin{array}{l}\text { - S1, S4, S5, S6 and S7 directly } \\
\text { influences the implementation of } \\
\text { T1 and achievement of P1 }\end{array}$ \\
\hline Planning & $\begin{array}{l}\text { P2 - Realistic } \\
\text { elemental cost } \\
\text { targets }\end{array}$ & $\begin{array}{l}\text { - T1 and T2 directly } \\
\text { influences the } \\
\text { achievement of P2 }\end{array}$ & $\begin{array}{l}\text { - S1, S2, S3, S4, and S5 directly } \\
\text { influences the implementation of } \\
\text { T1 and T2 and achievement of P2 }\end{array}$ \\
\hline Budgeting & $\begin{array}{l}\text { P3 - Operational } \\
\text { cost } \\
\text { performance } \\
\text { baseline }\end{array}$ & $\begin{array}{l}\text { - T2 and T8 directly } \\
\text { influences the } \\
\text { achievement of P3 } \\
\text { - T1 indirectly influences } \\
\text { the achievement of P3 }\end{array}$ & $\begin{array}{l}\text { - S3, S4, S5, S6 and S7 directly } \\
\text { influences the implementation of } \\
\text { T2 and T8 and achievement of P3 }\end{array}$ \\
\hline Monitoring & $\begin{array}{l}\text { P4 - Positive cost } \\
\text { performance } \\
\text { index }\end{array}$ & $\begin{array}{l}\text { - T3, T4, T5, T6 and T7 } \\
\text { directly influences the } \\
\text { achievement of P4 } \\
\text { - } \mathrm{T} 1 \text { and } \mathrm{T} 2 \text { indirectly } \\
\text { influences the } \\
\text { achievement of P4 }\end{array}$ & $\begin{array}{l}\text { - S2 directly influences the } \\
\text { implementation of T5 and } \\
\text { achievement of P4 only } \\
\text { - S3, S4, S5, S7, S8 and S9 directly } \\
\text { influences the implementation of } \\
\text { T3, T4, T5, T6, T7 and } \\
\text { achievement of P4 }\end{array}$ \\
\hline
\end{tabular}

The brainstorming session in Stage 3 was also used to pre-validating initial findings; particularly to ensure that the model reflected 'reality' concerning the components of CMS. Given that the core rationale of this model was to purposefully capture and represent the interrelationships between techniques and success drivers (at each stage of the cost management process), it was important to embed these relationships to check the veracity of links and dependencies. Based on the findings and feedback from this session, the model was iteratively modified and refined to provide additional clarity on outcomes and specificity required to meet LHP needs. This model is presented in Figure 5. 


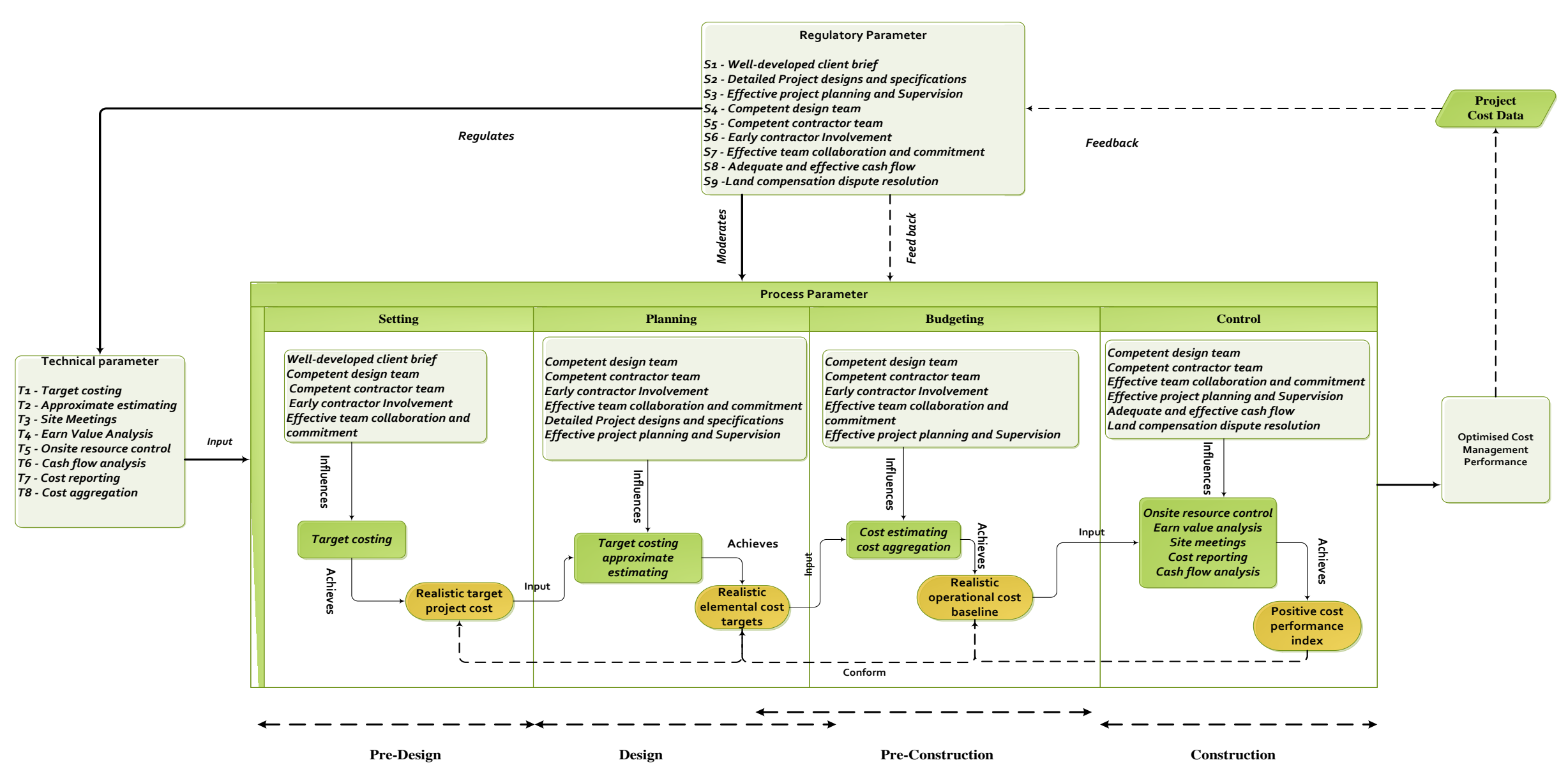

Figure 5: LHP Cost Management Model for Process Integration and Evaluation 
Figure 5 presents a model for capturing and evaluating the process integration requirements for CMS within the context of LHP. The model presents: a technical parameter (with eight techniques), a regulatory parameter (with nine success drivers) and a process parameter (with a cost- design-control process approach with four performance criteria). The interactions of these three parameters form an effective cost management approach for performance management. The continuous feedback from the process stages feeds into the control parameter in order to enable effective choice of techniques to employ and accompanying regulation. The following four process stages are presented for discussion.

\subsubsection{Setting Stage:}

This involves setting the context and refers to the determination of the project target cost based on the business case and not just approximate estimates (Zimina et al., 2012). The first stage starts with establishing processes at the pre-design stage of the project. Target costing is used for setting the target cost, as this embodies value engineering and life-cycle costing in its procedure. This approach also allows the consideration of 'allowable costs' based on government budgets and affordability of target beneficiaries. This also facilitates the evaluation of various designs and specifications suitable for meeting projected beneficiaries requirements. This is considered particularly appropriate for LHP. That being said, it is important to acknowledge that considerable effort is required to develop a realistic target cost at this stage. In this respect, it is important to consider the target cost implementation techniques for the four key success drivers: i) competent design and construction team, ii) early contractor involvement, iii) 
effective team collaboration and commitment and (iv) well-developed client project brief.

\subsubsection{Planning Stage:}

The planning stage refers to the process of distributing the project target costs into elemental cost targets for each element of the building (Ostrowski, 2013; Kirkham, 2014). This process directly aligns with the project design stage. Target costs and approximate estimating techniques are used to establish realistic elemental cost targets for the project. These techniques enable detailed cost estimate, and formal cost plans to be produced in accordance with strict adherence policies associated with target project costs. This also helps ensure other issues such as value for money considerations are addressed. The planning stage also establishes the protocols required, including the establishment of a competent design team and contractor (so that these teams are engaged at the earliest opportunity). Other issues include the need to establish welldefined and detailed project design and specifications, including an effective project planning approach and engagement of appropriate supervisory control measures needed to ensure these techniques are suitably implemented.

\subsubsection{Budgeting Stage:}

This stage envelops the aggregation of costs into a work breakdown structure along the project timeline. Budgeting is an essential part of the process as it provides a system for monitoring costs (Asworth, 2010; Azis, et al., 2012). The budgeting stage aligns with the project pre-construction stage; although, some might argue that this could start at the end of the project design stage. Notwithstanding this, two main techniques are employed in this stage: approximate estimating and cost aggregation. The combination of these two techniques allows effective cost breakdown structure to be established, which are then integrated into the schedule to establish an operational cost performance 
baseline for the project. All the drivers from the planning stage are essential in this process, as these drivers facilitate the characteristics needed to develop a realistic timeline (upon which costs can be scheduled). These are then used to establish the cost performance index for monitoring during construction.

\subsubsection{Control Stage:}

The control stage is used for monitoring performance against the set plans. This also includes the mechanisms needed to take proactive/corrective action to ensure the objectives are met (Morad \& El Sayegh 2016). This stage aligns with the project construction stage. To realise the cost performance index, this stage presents five techniques: i) site meetings, ii) onsite project resource control, iii) EVA, iv) cost reporting and v) cash flow analysis. This naturally includes issues many peripheral issues such as: cash flow, resolution of land compensation, operational baseline etc. At this juncture it is important to recognise that the LHP environment (and contextual setting) can often influence how the control measures are enacted; as from a Nigerian perspective, subtle nuances and bureaucratic protocols typically affect cash flow and cost control. The control stage is therefore used to ensure activities are aligned, from the provision of working capital needed to support daily site activities, through to procedures needed for managing project resources, and strategies for mitigating disruptions.

\subsection{Stage 4: Model Validation}

This model was developed for a specific purpose. As such, it was important that its validity was confirmed regarding its suitability, context and appropriateness to its intended users (Bernard and Ryan 2010; Sargent, 2013). Thus, the validation process employed a focus group conducted conventionally comprising of eight construction 
experts (six PMT experts and two academics) - the details of which can be seen in Table 2. Some of the participants were physically present and others were remotely contacted. This method was employed because it allows the exploration of the merits and demerits of a number of pre-identified solutions in a highly structured manner (Gill et al., 2008). The purpose of the validation was for participants to assess the clarity, appropriateness, and usefulness of the proposed model in assisting PMTs to achieve effective cost management practice towards optimised cost management performances in Nigerian LHP settings.

Table 2: Participant Profile

\begin{tabular}{|c|c|c|c|c|}
\hline $\begin{array}{c}\text { Participant } \\
\text { Organisation }\end{array}$ & Job Title & $\begin{array}{c}\text { Professional } \\
\text { Background }\end{array}$ & $\begin{array}{c}\text { Cost } \\
\text { Management } \\
\text { Experience } \\
\text { (years) }\end{array}$ & $\begin{array}{c}\text { LHP Project } \\
\text { Experience } \\
\text { (years) }\end{array}$ \\
\hline Housing Agency & Project Manager & Quantity Surveyor & 25 & 17 \\
\hline Housing Agency & Project Supervisor & Architect & 11 & 13 \\
\hline Consultant & $\begin{array}{c}\text { Consultant } \\
\text { Quantity Surveyor }\end{array}$ & Quantity Srveyor & 10 & 10 \\
\hline Consultant & $\begin{array}{c}\text { Consultant } \\
\text { Architect }\end{array}$ & Architect & 19 & 15 \\
\hline Contractor & Site Manager & Builder & 13 & 9 \\
\hline Contractor & Site Manager & Architect & 15 & 7 \\
\hline University & Academic & Quantity Surveyor & 32 & 4 \\
\hline University & Academic & Structural Engineer & 19 & 5 \\
\hline
\end{tabular}

\section{Discussion}

Feedback from the validation exercise highlighted that the model reflected CMS reality and that relationships mirrored the techniques currently employed. The inclusion of additional rigour and application of success drivers at each stage of the process was considered particularly beneficial, as these acted as 'stage gates' for monitoring and control purposes. Whilst the model was described as being relatively easy to understand 
(by the majority of participants), it was accepted that complexity had to be counterbalanced with usability, particularly with respect to 'accepted’ CMS procedures, and users' familiarity of these (within LHP settings).

A number of core observations can be drawn from this study. The following narrative highlights six refection points:

- The need to employ expert judgement - not only throughout the whole cost management process but holistically in order to ensure the integrity of vertical and horizontal parameters. Team competence engaging expert judgement at various stages is considered a potent strategy for ensuring effective cost management implementation (Rwelamila, 2012; Obi et al., 2017; Sinesilassie et al., 2018). In this respect, it is advocated that housing agencies and project managers in their prequalification practices rely upon the tenets of the cost management process when formulating the selection criteria to assess the competency of all PMT members. This will ensure they possess the prerequisite technical and soft skills needed to discharge professional duties associated with cost management processes and associated techniques prior to their engagement

- The need to facilitate early contractor involvement on LHPs. This is particularly important for facilitating early team integration, but can also help provide an enabling environment for making strategic decisions from the outset. This resonates with previous studies (Jacomit and Granja, 2011; Obi et al., 2017) where early contractor involvement provides a platform for greater collaboration - predominantly for harnessing knowledge and experience to support project outcomes; where possible two-stage design and build or a construction management procurement system could be adopted to encourage the early 
integration of expertise in construction management relevant to the cost management process.

- $\quad$ The need to engage verification processes. Where (for example), housing agencies can verify that PMT's have a detailed understanding of all project requirements. This concurs with previous studies which highlight the need for a clear and well-understood project brief, along with an experienced managerial project team - as this alignment provides greater opportunities for delivering anticipated results (Olawale \& Sun, 2013; Sinesilassie et al., 2018). This requirement also helps ensure project resources are directly aligned to set objectives in order to help improve cost and affordability;

- The need to apply collaborative practices. Mechanisms should be in place for engaging project managers with the entire project team. This is crucial, as some LHPs project team members may not have appropriate project management capabilities needed for discharging their respective duties. This echoes with Ahadzie and Amoa-Mensah (2010) who argue the importance of setting the stage for initial training and discussions; including project 'walkthroughs' to set the team 'mindset' needed. Workshops are particularly useful in this respect, as they allow detailed discussion on how the cost management processes and techniques can be implemented - including the roles of various parties to improve productivity, efficiency and delivery;

- The need for continuous feedback. The type, structure and process of communication engaged in LHP project delivery invariably influences a raft of corollary issues, not least cost and efficiency outcomes. This correlation needs to be fully understood from the outset as proactive and timely action can often mitigate negative cost variances (Sanvido, 1998; Kern \& Formoso, 2006; 
Windapo, 2013). The incorporation of effective feedback mechanisms and policies should be implemented and regularly maintained in order to ensure the results from each process are captured, verified and reported to appropriate teams. Information transparency can also help promote trust; but more importantly, provides formal conduits for responsibility and accountability (Sinesilassie et al. 2018).

- The need to capture and store all project data is paramount. It is important to engage a cogent system for capturing and storing all processes, documentation and associated cost data at all stages of the project. This includes tacit and explicit knowledge underpinning LHP decisions. A legacy archive is recommended for future organisational learning - see, for example, Goulding and Alshawi (2002).

\section{Conclusion}

This study outlined the need to develop an appropriate structured model for cost management practice within LHP settings as previous undertakings have not yet been able to purposefully capture and represent intrinsic system components or CMS interrelationships. In this respect, several challenges were highlighted, including contextual positioning, costing terminologies and boundaries, and role diversity/thinking. Acknowledging these challenges, this research engaged a Systems Theory approach to unpack these issues, given the need to embrace interrelated and interdependent facets, boundaries, environmental context and operational dynamics. In doing so, it was proffered that this approach could help provide additional clarity for cost management practice.

An explicit sequential mixed methodology research strategy was used to develop a "LHP Cost Management Model for Process Integration and Evaluation”; which was 
designed specifically to help PMT’s optimise LHP cost management practice in Nigeria. This incorporated eight techniques, regulated by nine success drivers. These are aligned to the pre-design, design, and pre-construction and construction stages of LHP. The model standardises cost management practice to provide a systematic 'blueprint' for managing CMS processes. Core findings include the need to appoint early contractor involvement in order to not only improve collaborative practice and strengthen decision making, but also the need to verify project team competence beforehand. Early appointment was also seen as a fertile lever for improving the communication conduits needed for effective project delivery.

From a contribution to knowledge perspective, this research provides new insight and understanding into the formal mechanisms and complex interrelationships that exist in LHP CMS models. This includes the success drivers and process parameters needed for effective operationalisation. From a generalisability and repeatability perspective, whilst this model was developed for the Nigerian LHP sector, methodologically, there are a number of areas that are directly transferable to other contexts, not least, the importance of establishing technical, control and process parameters. From an operationalisation perspective, these areas require additional research to establish the control mechanisms, impact areas, and doctrines needed to meet local, context or domain-driven needs. In summary, findings from this research are, therefore, purely bound to this sample frame. Future research imperatives include the need to involve greater detailed cross-analysis/correlation in order to support internal/external consistency, validity and reliability for different markets (mature/ immature) and settings (countries, socio-economic systems etc.). 


\section{References}

Adinyira, E., Botchway, E. \& Kwofie, T.E. (2012). Determining critical project success criteria for public housing building projects (PHBPS) in Ghana. Engineering Management Research, 1(2), 122-132.

Ahiaga-Dagbui, D., Smith, S. D., Love, P. E. D., \& Ackermann, F. (2015, September). Spotlight on construction cost overrun research: Superficial, replicative and stagnated. In A. B. Raidén \& E. Aboagye-Nimo (Eds.), ARCOM 2015. Proceedings of 31st Annual ARCOM Conference (pp. 863-872), Lincoln, UK: Association of Researchers in Construction Management.

Ahadzie, D.K., \& Amoa-Mensah, K. (2010). Management practices in the Ghanaian house building Industry. Journal of Science and Technology 30 (2), 62-75.

Akinde, S. B. (2012). Lean implementation towards effective low-cost housing design and construction delivery in Nigeria (Unpublished master’s thesis). University of Salford, Manchester, UK.

Alashwal, A.M., Rahman, H.A., \& Beksin, A.M. (2011). Knowledge sharing in a fragmented construction industry: On the hindsight. Scientific Research and Essays, 6(7),1530-1536.

Ashworth, A. (2010). Cost Studies of Buildings (2nd ed.). Harlow England: Pearson Education Limited.

Azis, A.A.A., Memon, A.H., Rahman, I.A., Latif, Q.B.A.I., \& Nagapan, S. (2012, September). Cost management of large construction projects in South Malaysia. Proceedings of 2012 IEEE Symposium on business, engineering and industrial applications (625-629). Bandung Indonesia: IEEE.

Benjaoran, V. (2009). A cost control system development: A collaborative approach for small and medium-sized contractors. International Journal of Project Management, 27 (3), 270 - 277.

Bernard, H.R., \& Ryan, G.W. (2010). Analyzing qualitative data: Systematic approaches. Thousand Oaks: US. Sage Publications.

Chigara, B., Moyo, T., and Mudzengerere, F.H. (2013). An analysis of cost management strategies employed by building contractors on projects in Zimbabwe. International Journal of Sustainable Construction Engineering and Technology, 4(2), 1-13. 
Denzin, N.K., \& Lincoln, Y.S. (2011). The SAGE Handbook of Qualitative Research. London, UK: SAGE Publications.

Enshassi, A., Mohamed, S., \& Abdel-Hadi, M. (2013). Factors affecting the accuracy of pre-tender cost estimates in the Gaza Strip. Journal of Construction in Developing Countries, 18 (1) 73-94.

Famiyeh, S., Amoatey, C. T., Adaku, E., and Agbenohevi, C. S. (2017). Major causes of construction time and cost overruns: A case of selected educational sector projects in Ghana. Journal of Engineering, Design and Technology, 15 (2), 181198.

Federal Ministry of Lands Housing and Urban Development (FMLHUD) (2012). National Housing Policy. Abuja, Nigeria: Government press.

Gao, Z., Smith, G., \& Minchin, R. (2002). Budget and schedule success for small capital facility projects. Journal of Management in Engineering, 18 ( 4), 186 193.

Gill, P., Stewart, K., Treasure, E., \& Chadwick, B. (2008). Methods of data collection in qualitative research: interviews and focus groups. British Dental Journal, 204(6), 291-295.

Gorog, M. (2009). A comprehensive model for planning and controlling contractor cashflow. International Journal of Project Management, 27(5), 481 - 492.

Goulding J.S, \& Alshawi M, (2002). Generic and Specific IT Training: A process protocol model for construction. Journal of Construction Management and Economics, 20 ( 6), 493-505.

Hartley, J. (2014). Some thoughts on Likert-type scales. International journal of clinical and health psychology, 14(1), 83-86.

Hatamleh, M. T., Hiyassat, M., Sweis, G. J., \& Sweis, R. J. (2018). Factors affecting the accuracy of cost estimate: Case of Jordan. Engineering, Construction and Architectural Management, 25(1), 113-131.

Holt, G.D., \& Goulding, J.S. (2014). Conceptualisation of ambiguous-mixed-methods within building and construction research. Journal of Engineering, Design, and Technology, 12(2), 244-262.

Horngren, C.T., Foster, G., Datar, S. M., Rajan, M., and Ittner, C. (2009). Cost Accounting: A managerial emphasis. (13th ed.). Upper Saddle River, NJ, USA: Pearson Prentice Hall. 
Jacomit, A. M., \& Granja, A. D. (2011). An investigation into the adoption of target costing on Brazilian public social housing projects. Architectural Engineering and Design Management, 7(2), 113-127.

Kern, A.P. \& Formoso, C.T. (2006). A model for integrating cost management and production planning and control in construction. Journal of Financial Management of Property and Construction, 11(2), 75-90.

Kirkham, R. (2014). Ferry and Brandon's cost planning of buildings. West Sussex UK: Wiley-Blackwell

Liu, L., \& Zhu, K. (2007). Improving cost estimates of construction projects using phased cost factors. Journal of Construction Engineering and Management, 133(1), 91-95.

MacCuspie, R. I., Hyman, H., Yakymyshyn, C., Srinivasan, S. S., Dhau, J., \& Drake, C. (2014). A framework for identifying performance targets for sustainable nanomaterials. Sustainable Materials and Technologies, 1, 17-25.

Morad, M., \& El-Sayegh, M.S. (2016, May). Use of earned value management in the UAE construction industry. In S. Park, X., Huang \& N. Joukov. Proceedings of 2016 International Conference on Industrial Engineering, Management Science and Application (ICIMSA),( pp. 1-5). Jeju South Korea: IEEE.

Obi, L.I., Arif, M., \& Kulonda, D.J. (2017). Prioritising cost management system considerations for Nigerian housing projects. Journal of Financial Management of Property and Construction, 22 (2), 135-153.

Ogbu, C.P., \& Adindu, C.C. (2012). Project management approach to public lowincome housing, Journal of Research in National Development, 10 (2), 142-153.

Oladapo, M.A. (2001, October). A framework for cost management of low-cost housing. Paper presented at the International Conference on Spatial Information for Sustainable Development, Nairobi, Kenya Nairobi.

Olawale, Y. \& Sun, M. (2013). PCIM: A project control and inhibiting-factors management model. ASCE Journal of Management in Engineering, 29( 1), 6070.

Omotayo, T., and Kulatunga, U. (2017). A continuous improvement framework using IDEF0 for post-contract cost control. Journal of Construction Project Management and Innovation, 7 (1), 1807-1823. 
Ostrowski, S. D. (2013). Estimating and cost planning using the new rules of measurement. West Sussex UK: Wiley-Blackwell.

Pallant, J. (2013). SPSS Survival Manual (5th ed.). New York, US: McGraw-Hill Education.

Potts, K. (2008). Construction cost management: learning from case studies. Oxon UK: Routledge.

Sargent, R.G. (2013). Verification and validation of simulation models. Journal of simulation, 7 (1), 12-24.

Sanvido, V.E. (1988). Conceptual construction process model. Journal of Construction Engineering and Management,114(2), 294-310.

Saunders, M., Lewis, P. \& Thornhill, A. (2012). Research Methods for Business Students (6th ed.). Harlow UK: Pearson Education Ltd.

Shrestha, P.P. \& Mani, N. (2013). Impact of design cost on project performance of design-bid-build road projects. Journal of Management in Engineering, 30 (3), 04014007-1-8

Sinesilassie, E.G., Tabish, S.Z.S., \& Jha, K.N. (2018). Critical factors affecting cost performance: A case of Ethiopian public construction projects. International Journal of Construction Management, 18(2), 108-119. https://doi.org/10.1080/15623599.2016.1277058

Smith, P. (2014). Project Cost Management-Global Issues and Challenges. ProcediaSocial and Behavioral Sciences, 119, 485-494.

Stephenson, H.L (2015). AACE International Total Cost Management Framework: An Integrated Approach to Portfolio, Program, and Project Management. (2nd ed.) Morgantown, USA: CreateSpace Independent Publishing Platform.

Tang, W. (2005). Cost management for building contractors in Hong Kong (master's thesis). Available from HKU Libraries Theses and Dissertations database.( b3160121)

Toor, S.U.R., \& Ogunlana, S.O. (2010). Beyond the ‘iron triangle’: Stakeholder perception of key performance indicators (KPIs) for large-scale public sector development projects. International Journal of Project Management, 28 (3), 228-236. 
Trost, S.M. \& Oberlender, G.D. (2003). Predicting the accuracy of early cost estimates using factor analysis and multivariate regression. Journal of Construction Engineering and Management, 129 (2), 198-204.

United Nations Human Settlements Programme (UN-Habitat) (2012). Affordable land and housing in Africa. (Report N0. 076/11E ). Retrieved from UN-Habitat website https://unhabitat.org/affordable-land-and-housing-in-africa.

Windapo, A. (2013). Fundamentals of Construction Management. Retrieved from bookboon.com http://thuvienso.bvu.edu.vn/bitstream/TVDHBRVT/15398/1/Fundamentals-ofConstruction-Management.pdf

Zimina, D., Ballard, G., \& Pasquire, C. (2012). Target value design: using collaboration and a lean approach to reduce construction cost. Construction Management and Economics, 30 (5), 383-398. 